\title{
A Study on the Meaning and Usage of Auditory Verbs in English by English Learners
}

\author{
Masanobu Sato
}

\begin{abstract}
This study explored how Japanese learners of English understand the verbs of perception in English with reference to auditory verbs. 61 Japanese college students, who participated in this study, were divided into three groups according to their TOEIC scores in a placement test. A set of three questionnaires were devised in order to examine 1) their ability to choose the right verb in context, 2) their awareness about the formulaic expressions using listen and hear, and 3) their sensitivity to the well-formedness of expressions using listen and hear. The overall results of the study showed that Japanese learners generally have trouble in handling even these basic verbs. It was also found that there are level-sensitive trouble areas.
\end{abstract}

Index Terms-Auditory verbs, lexical core, lexical selection, search-translation-equivalent strategy.

\section{INTRODUCTION}

In this paper, we are interested in how Japanese learners approach the task of developing their lexical competence in English. Previous studies have shown that Japanese learners have trouble in acquiring the competence of using basic words such as dimensional adjectives [1], the basic verbs like give [2] and put [3], the verbs of vision [4], the verbs of utterance [5]. These studies uniformly suggest that basic words in English are hard to acquire, and that lexical errors in the domain of basic words are common, regardless of the level of proficiency in English. In this study, we focus on the basic verbs in the auditory domain, one of the five organ domains (the olfactory, taste, visual, auditory, and tactile domains), and investigate the Japanese learner's understanding about the meaning and usage of listen, hear, and sound.

In this study, we designed this research based on the semantics of basic auditory verbs, and asked Japanese university students learning English in an instructional setting to answer the test. The next section briefly explains the semantics of basic auditory verbs.

\section{ThE SEMANTICS OF BASIC AUdITORY VerbS}

Semantically, we can identify three semantic phases in each perceptual domain: 1) the action phase, 2) the experience phase, and 3) the result phase [6]-[8]. Here, "action" refers to a process that is consciously controlled by a human agent, whereas "experience" refers to a state that is not controlled. And "result" refers to the impression one gets as a result of

Manuscript received December 9, 2014; revised February 3. 2015.

Masanobu Sato is with Keio University, Japan (e-mail: kizuna238@yahoo.co.jp). using one of the five-sense organs. The phase of "action" and "result" are in a reflexive relationship. To illustrate, let us take a look at the following sentences:

1) Action: She smelled the curry to make sure it was still good.

2) Experience: She smelled curry when she entered the house.

3) Result: The curry smelled good.

Syntactically, sentences 1 and 2 have a similar construction "she smelled the curry / curry," both taking the agent (i.e., she) as the subject, and the object (i.e., the curry) as the complement. However, there is a semantic difference, and the difference becomes clear once we consider the presumable contexts that the two sentences assume: In sentence 1, a woman made curry two days ago, and wanted to have it. In sentence 2 , her husband had made curry while she was away, and she just got home. In other words, in sentence 1, a woman did the action of smelling and the target of smelling was the curry, while in sentence 2, a woman's nose sensed something, and the something was a smell of curry. The smell of sentence 1 highlights the action phase of smelling, and the smell of sentence 2 highlights the experience phase of smelling.

Both sentences take the agent as the subject. On the other hand, in sentence 3, the subject is the object or the target of smelling (i.e., the curry), and the agent of doing the smelling is put behind the scene. Sentence 3 describes what impression the hidden agent had as a result of the action (i.e., smelling the curry). The action "smell" and the result "smell" are thus in a reflexive relationship.

In the auditory domain, as the following examples show, each phase is expressed by a different verb:

1) The action phase: He listened to what I said.

2) The experience phase: He heard a voice coming from the outside.

3) The result phase: The voice sounded urgent.

The point here is that when dealing with verbs of five sense organs, we should consider three semantic phases. This study focuses on the auditory domain, where listen, hear, and sound are used to refer to the three phases. The aim of this research was, then, to explore the following research questions:

1) How much do Japanese university students of different English levels have their ability to select the right verb among listen, hear and sound in context?

2) How much are Japanese university students of different English levels familiar with the formulaic usages of hearing and listening?

3) How much are Japanese university students of different English levels sensitive to the well-formedness of constructions using hear and listen?

These questions assume that the lexical competence of 
auditory verbs involve the ability to select the appropriate verb in context, the awareness about the formulaic usages of each verb, and the sensitivity to syntactic or constructional possibilities of each verb.

\section{METHOD}

The participants were 61 Japanese university students who had been taking English courses, and two native speakers of English were asked to be the informants when constructing the questionnaire. At the start of a new semester, these Japanese students were divided into three groups or classes: the level-1 group $(n=23)$, the level-2 group $(n=22)$, and the level-3 group $(n=16)$, on the basis of their scores on a placement test (the TOEIC), which they had taken at the beginning of the semester. The participants were also asked to self-assess their level of proficiency in English on a 10-point scale, with 10 being the highest.

Three kinds of tests were devised to investigate the above-mentioned research questions. Test 1 (Lexical Selection Test) intended to measure the ability to select the appropriate word among listen, hear, and sound in a sentence with the contextual information given in Japanese. Test 2 (Idiom Awareness Test) was devised to measure the learner's awareness about formulaic uses of the two basic auditory verbs. Test 3 (Grammaticality Judgment Test) asked the participants whether a sentence - a grammatically modulated sentence - sounds right or wrong. Before answering the three tests, the participants were asked to rate the confidence of their English proficiency on a 10-point scale, with 1 being the lowest, and 10 being the highest. Of the 9 questions included in the Lexical Selection Test, a set of 3 items corresponded to one of the three phases (i.e., action, experience, and result). The participants were also asked to rate their confidence level when choosing the appropriate verb on a three-point scale, with 1 being the lowest, and 3 being the highest. An example is given in Fig. 1 below:

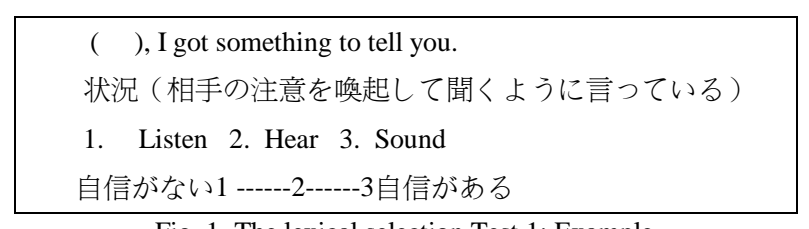

Fig. 1. The lexical selection Test 1: Example.

In the Idiom Awareness Test, there were 8 expressions (e.g., "Hear me out.") using hear or listen, which were considered idiomatic. Japanese learners are familiar with the collocation "listen to." However, the verb listen can be used in "Listen up" or "Now, listen." Here, the question was how much Japanese learners are aware of or familiar with the formulaic expressions given in the test. This test asked the participants to choose the appropriate verb between listen and hear (see Fig. 2).

\section{彼女は翌朝その事故について聞いた。 \\ She (heard / listened)about the accident the next morning.}

Fig. 2. The idiom awareness Test 2: Example.

Another test was administered to the participants to check their grammatical sensitivity to 8 sentences grammatically modulated with respect to the use of adverbs, the progressive aspect, and the $\mathrm{V}+\mathrm{NP}+$ present participle (-ing) construction. For example, an adverb like suddenly was added to a sentence like "I listened to a strange sound" to make it sound strange. The test contained 8 sentences, and the participants were asked to judge whether the sentence is correct or incorrect, by putting the mark " $\bigcirc$ " or " $\times$ " - following the Japanese convention - in the space next to the sentence (see Fig. 3).

Suddenly I listened to a strange noise. $(X)$

Fig. 3. The grammaticality judgment Test 3: Example.

The volume of each test was reduced to a minimum size in order to reduce the task burden on the part of the participants. A set of these tests were administered in a classroom. As the instructor for each class, I was able to give clear directions. It took about 15 minutes to complete the task. Students were asked to put down their names and complete all the questions in order to obtain good data. The results of the study were later introduced and discussed in class.

\section{RESULTS AND DISCUSSION}

The 61 Japanese university students in three different level groups were asked to assess their level of confidence in their English on a 10-point scale, with 1 being lowest, and 10 being highest. The level-1 group had a general tendency to rate their confidence lower that their actual level and most of them rated their confidence level within the range of 1 to 3 . This seems to suggest that lower students do not have much confidence in their English skills. This does not, however, uniquely apply to the level-1group. Most students regardless of their level of proficiency tended to underestimate their competence level. By and large, however, there was a statistically significant positive correlation between their score-based level and their perceived level of confidence $(r=0.503, p=<.001, n=61)$.

\section{A. The Results from the Lexical Selection Test}

Let us now take a look at the results obtained from Test 1 , which intended to measure the ability to select the appropriate verb among listen, hear, and sound to complete a sentence. Table I shows the overall results.

We carried out a two-way ANOVA using SPSS statistics, as well as Tukey's Tests for multiple comparisons. Overall, there was a significant difference between the three groups $(\mathrm{F}$ $(548,2)=18.622, p .<.001)$. The more advanced learners in the level-3 group scored higher than the less advanced learners in the level-1 and level-2 groups, although there was no significant difference between the level-1 group and the level-2 group. The participant's confidence level, with 3 being the strongest and 1 the weakest, when answering each question, as shown in Table II.

By and large, our students answered each question with less confidence, with 2.0 being the midpoint on the scale of confidence.

Of the 9 items, item 6 received the lowest score $(27.5 \%)$ followed by the score $(32.8 \%)$ for item 5 . This is true of the level-2 group and the level-1 group. The perceived level of confidence in the answer for 6 is low across the different groups. On the other hand, the highest score was obtained for 
item $9(88 \%)$ among the level-3 group, for item 1(73\%) among the level-2 group, and for item 7(61\%) among the level-1 group. The expression "That sounds like ...." is a formula which appears on school textbooks frequently. Most Japanese learn the formulaic expression during their junior high school years.

TABLE I: THE PERCENTAGES OF THE CORRECT ANSWERS By THE LEVEL OF PROFICIENCY

\begin{tabular}{ccccc}
\hline Test Items & $\begin{array}{c}\text { Levels } \\
1(n=23)\end{array}$ & $2(n=22)$ & $3(n=16)$ & Mean \\
\hline $\begin{array}{c}\text { 1. I like (listening to) } \\
\text { Yoko playing the } \\
\text { piano. }\end{array}$ & $52.2 \%$ & $72.7 \%$ & $62.5 \%$ & $62.3 \%$ \\
$\begin{array}{c}\text { 2. (Listen), I got } \\
\text { something to tell you. }\end{array}$ & $21.7 \%$ & $40.9 \%$ & $56.3 \%$ & $37.7 \%$ \\
$\begin{array}{c}\text { 3. He (sounded) very } \\
\text { urgent on the phone. }\end{array}$ & $21.7 \%$ & $40.9 \%$ & $75.0 \%$ & $42.6 \%$ \\
$\begin{array}{c}\text { 4. He (heard) his name } \\
\text { called. }\end{array}$ & $47.8 \%$ & $45.5 \%$ & $68.8 \%$ & $52.5 \%$ \\
$\begin{array}{c}\text { 5. Don't (listen to) such } \\
\text { a guy. }\end{array}$ & $21.7 \%$ & $36.4 \%$ & $43.8 \%$ & $32.8 \%$ \\
$\begin{array}{c}\text { 6. Do these sentences } \\
\text { (sound) right? }\end{array}$ & $8.7 \%$ & $22.7 \%$ & $68.8 \%$ & $29.5 \%$ \\
$\begin{array}{c}\text { 7. I (heard) that your } \\
\text { grandfather is ill. }\end{array}$ & $60.9 \%$ & $54.5 \%$ & $75.0 \%$ & $62.3 \%$ \\
$\begin{array}{c}\text { 8. My grandmother } \\
\text { doesn't (hear) very } \\
\quad \text { well. }\end{array}$ & $39.1 \%$ & $22.7 \%$ & $75.0 \%$ & $42.6 \%$ \\
$\begin{array}{c}\text { 9. That (sounds) like a } \\
\text { gunshot. }\end{array}$ & $56.5 \%$ & $59.1 \%$ & $87.5 \%$ & $65.6 \%$ \\
\hline$\quad$ Mean & $36.7 \%$ & $43.9 \%$ & $68.1 \%$ & $47.5 \%$ \\
\hline
\end{tabular}

TABLE II: THE CONFIDENCE LEVEL IN ANSWERING THE ITEMS

\begin{tabular}{|c|c|c|c|c|}
\hline \multirow{2}{*}{ Test Items } & \multicolumn{3}{|l|}{ Levels } & \multirow{2}{*}{ Mean } \\
\hline & $1(n=23)$ & $2(n=22)$ & $3(n=16)$ & \\
\hline $\begin{array}{l}\text { 1. I like (listening to) Yoko } \\
\text { playing the piano. }\end{array}$ & 1.57 & 1.77 & 2.06 & 1.77 \\
\hline $\begin{array}{l}\text { 2. (Listen), I got something } \\
\text { to tell you. }\end{array}$ & 1.61 & 1.55 & 2.25 & 1.75 \\
\hline $\begin{array}{l}\text { 3. He (sounded) very } \\
\text { urgent on the phone. }\end{array}$ & 1.52 & 1.50 & 2.06 & 1.66 \\
\hline $\begin{array}{l}\text { 4. He (heard) his name } \\
\text { called. }\end{array}$ & 1.57 & 1.41 & 1.94 & 1.61 \\
\hline $\begin{array}{l}\text { 5. Don't (listen to) such a } \\
\text { guy. }\end{array}$ & 1.52 & 1.55 & 1.56 & 1.54 \\
\hline $\begin{array}{l}\text { 6. Do these sentences } \\
\text { (sound) right? }\end{array}$ & 1.52 & 1.45 & 2.00 & 1.62 \\
\hline $\begin{array}{l}\text { 7. I (heard) that your } \\
\text { grandfather is ill. }\end{array}$ & 1.57 & 1.32 & 2.19 & 1.64 \\
\hline $\begin{array}{l}\text { 8. My grandmother doesn't } \\
\text { (hear) very well. }\end{array}$ & 1.74 & 1.36 & 1.63 & 1.57 \\
\hline $\begin{array}{l}\text { 9. That (sounds) like a } \\
\text { gunshot. }\end{array}$ & 1.65 & 1.55 & 2.19 & 1.75 \\
\hline Mean & 1.58 & 1.49 & 1.99 & 1.66 \\
\hline
\end{tabular}

To see what phase is more problematic to Japanese learners, the results in Table 1 were categorized in Table III.

This table shows the action phase $(45.4 \%)$ is slightly more difficult than the remaining two phases, and that the phase of result $(49 \%)$ is more difficult than the experience phase $(54.4 \%)$. However, the differences between 3 phases were not statistically significant $(\mathrm{F}(8,2)=1.59, \mathrm{~ns})$. Yet, the variable "level" has a significant effect on the results here $(F(8,2)=$ $18.93, p<.001)$. There was a marked difference between the level-3 group and the level-1 and level-2 groups. We also observed a significant interaction between level and phase $(\mathrm{F}$ $(8,2)=2.996, p<0.05)$. The level-3 group scored consistently higher across the three phases. The level-1 group, however, did better than the level-2 group in the experience phase, which is the cause of the interaction effect. The reason is unclear. However, it seems that item 3 , which scored the lowest of the nine items, did not fit the participants' understanding of the use of listen.

TABLE III: The PERCENTAge of CoRrect ANSwERS AND the THreE PHASES IN THE AUDITORY DOMAIN

\begin{tabular}{|c|c|c|c|c|}
\hline \multirow{2}{*}{$\begin{array}{l}\text { Items within phases } \\
\underline{\text { Action verb }}\end{array}$} & \multicolumn{3}{|l|}{ Level } & \multirow{2}{*}{$\begin{array}{l}\text { Mean } \\
M\end{array}$} \\
\hline & $1(n=23)$ & $2(n=22)$ & $3(n=16)$ & \\
\hline $\begin{array}{l}\text { 1. I like (listening to) } \\
\text { Yoko playing the piano. }\end{array}$ & $52.2 \%$ & $72.7 \%$ & $62.5 \%$ & \multirow{3}{*}{$\begin{array}{l}45.4 \\
\%\end{array}$} \\
\hline $\begin{array}{l}\text { 2. (Listen), I got } \\
\text { something to tell you. }\end{array}$ & $21.7 \%$ & $40.9 \%$ & $56.3 \%$ & \\
\hline $\begin{array}{l}\text { 5. Don't (listen to) such a } \\
\text { guy. }\end{array}$ & $21.7 \%$ & $36.4 \%$ & $43.8 \%$ & \\
\hline$\underline{\text { Experience verb }}$ & $1(n=23)$ & $2(n=22)$ & $3(n=16)$ & $M$ \\
\hline $\begin{array}{l}\text { 4. He (heard) his name } \\
\text { called. }\end{array}$ & $47.8 \%$ & $45.5 \%$ & $68.8 \%$ & \multirow{3}{*}{$\begin{array}{l}54.4 \\
\%\end{array}$} \\
\hline $\begin{array}{l}\text { 7. I (heard) that your } \\
\text { grandfather is ill. }\end{array}$ & $60.9 \%$ & $54.5 \%$ & $75.0 \%$ & \\
\hline $\begin{array}{l}\text { 8. My grandmother } \\
\text { doesn't (hear) very well. }\end{array}$ & $39.1 \%$ & $22.7 \%$ & $75.0 \%$ & \\
\hline$\underline{\text { Result verb }}$ & $1(n=23)$ & $2(n=22)$ & $3(n=16)$ & $M$ \\
\hline $\begin{array}{l}\text { 3. He (sounded) very } \\
\text { urgent on the phone. }\end{array}$ & $21.7 \%$ & $40.9 \%$ & $75.0 \%$ & \multirow{3}{*}{$\begin{array}{l}49.0 \\
\%\end{array}$} \\
\hline $\begin{array}{l}\text { 6. Do these sentences } \\
\text { (sound) right? }\end{array}$ & $8.7 \%$ & $22.7 \%$ & $68.8 \%$ & \\
\hline $\begin{array}{l}\text { 9. That (sounds) like a } \\
\text { gunshot. }\end{array}$ & $56.5 \%$ & $59.1 \%$ & $87.5 \%$ & \\
\hline
\end{tabular}

As shown above, Japanese learners are, in general, familiar with a specific exemplar, "listen to music." From this, we assume that this exemplar-based understanding blocked them from accepting "Don't listen to such a guy," in which the noun phrase "such a guy" becomes the complement of the preposition to. The phrase "Don't listen to such a guy," if interpreted literally, does not make sense in that what is intended is that you shouldn't listen to what such a guy says." The expression "Listen, I've got something to tell you" is an often-used colloquial expression in daily conversation. There is a possibility that our students had encountered this expression when they took our test, and yet, it had not been taken in as part of their mental lexicon. One possible reason for their screening out this usage is that enough attention had not been paid to the expression at the time when it had appeared in a text. It is true that item 1 was comparatively an easy item, but we may note that $63 \%$ is relatively low for the level-3 group. The following two constructions are taught in high school:

1) I heard Mary playing the piano.

2) I listened to Mary playing the piano.

There is, however, a tendency that sentence 1) is more emphasized than sentence 2) in textbooks and exercise books. As a result, in the mind of the level-2 group, the principle of preemption operated, preferring hear over listen to in this context.

Although the level-3 group scored more than $50 \%$ for all the items except for item 4 , the level-1 and level-2 groups scored less than $50 \%$ for the 7 items, with items 1 and 7 being the exception. From this, we can claim that the ability to use auditory verbs increases along with the developmental stages. 
However, we should note that the overall results obtained by the level-1 and level-2 groups are far from satisfactory.

On the basis of our findings, we may speculate that Japanese learners have not been trained to learn synonymous verbs such as listen, hear and sound systematically. Their learning tactics is simply this: Memorize examples as they encounter. This strategy is not, however, effective because students are required to memorize different examples in isolation. The concept of synonymy means that it refers to a phenomenon where different words are semantically related. Listen, hear, and sound are synonymous. Thus, we expect that Japanese learners find it difficult to use them differentially. There is a need to use listen, hear and sound differently, but Japanese learners experience lexical confusion when they select a verb such as in Test 1. English listen, hear and sound are synonymous. English verbs listen, hear and sound correspond to Japanese kiku, thus forming the many-to-one cross-linguistic pattern. If so, it is pedagogically important to teach synonymy verbs in such a way as to see the interconnectedness of different senses of a word.

\section{B. The Results from the Idiom Awareness Test}

Let us now take a look at the results from Test 2, which measured the learner's awareness about the idiomatic usage of auditory verbs. The overall results are shown in table 4 . To reduce the test burden, only 8 items were tested. The participants were asked to choose the right verb in context. The results obtained from the level-3 group were generally good, with the only exception being item 8 (49\%). We can account for the relatively high scores on the remaining items by saying that our participants, especially in the level-3 group, encountered the formulaic uses of the auditory verbs, and they memorized them. For example, expressions like "hear from" and "hear of" appear even in a textbook for junior high school students, as shown earlier. The usage of "hear from" may be one of the well-known phrases for Japanese English learners since they learn it when they study the word "hear from" at the early English instruction. The same goes for "listen for." "Listen up" is also a formulaic expression often used by native teachers. Regarding item (8), they were not simply familiar with that expression. A post-test interview suggested that they never knew the expression, though it is a useful one.

TABLE IV: THE PERCENTAGES OF CORRECT ANSWERS IN THE IDIOM AWARENESS TEST

\begin{tabular}{|c|c|c|c|c|}
\hline Test Items & $\begin{array}{l}\text { Levels } \\
1(n=23)\end{array}$ & $2(n-22)$ & $3(n=16)$ & Mean \\
\hline 1. (Listen) up, everybody! & $47.8 \%$ & $36.4 \%$ & $81.3 \%$ & $52.5 \%$ \\
\hline $\begin{array}{l}\text { 2. She (heard) about the } \\
\text { accident the next } \\
\text { morning. }\end{array}$ & $69.6 \%$ & $59.1 \%$ & $87.5 \%$ & $70.5 \%$ \\
\hline $\begin{array}{l}\text { 3. I (listen) in to the radio } \\
\text { every morning. }\end{array}$ & $60.9 \%$ & $77.3 \%$ & $62.5 \%$ & $67.2 \%$ \\
\hline 4. I (hear) from my sister. & $69.9 \%$ & $77.3 \%$ & $93.8 \%$ & $78.7 \%$ \\
\hline $\begin{array}{l}\text { 5. I have never (heard) of } \\
\text { such a strange custom. }\end{array}$ & $69.9 \%$ & $50.0 \%$ & $87.5 \%$ & $67.2 \%$ \\
\hline $\begin{array}{l}\text { 6. She (listened) for the } \\
\text { steps of her husband. }\end{array}$ & $60.9 \%$ & $63.6 \%$ & $81.3 \%$ & $67.2 \%$ \\
\hline $\begin{array}{l}\text { 7. Please (listen) out for } \\
\text { the baby. }\end{array}$ & $26.1 \%$ & $54.4 \%$ & $68.8 \%$ & $47.5 \%$ \\
\hline 8. (Hear) me out. & $26.1 \%$ & $40.9 \%$ & $50.0 \%$ & $37.7 \%$ \\
\hline Mean & $53.8 \%$ & $57.4 \%$ & $76.6 \%$ & $61.1 \%$ \\
\hline
\end{tabular}

In the case of hearing, students are familiar with the transitive usage. However, there are formulaic expressions including "hear about," "hear from," "hear of", and "Hear me out." Interviews with students show that they have a fixed notion that listen takes to as a preposition. We included "listen up," "listen in (to)," "listen for," and "listen out for" in the Idiom Awareness Test. During the 9 years of English learning, we expect that our students might have encountered most of these expressions incidentally. A statistical analysis showed that there was no significant difference between the level groups $(\mathrm{F}(483,2)=2.78, \mathrm{~ns})$, though the difference was close to the significance level of 0.5 . A series of Tukey's post-hoc tests, the post-hoc tests for pair comparisons, showed that of the 8 items in the test, item $1(\mathrm{~F}(60,2)=4.25)$, item $5(\mathrm{~F}(60$, $2)=3.17)$, and item $7(\mathrm{~F}(60,2)=4.11)$ showed a statistically significant effect of the level difference $(p>0.05)$

For the most part, formulaic usages are a matter of memory. More than $70 \%$ of the level-3 students chose the correct verbs across the 8 questions, followed by the $57 \%$ of the level- 2 and the $53 \%$ of the level-1 students. Overall, our students did fairly well on this test. This does not, however, mean that they are able to use them in an interactional context. In an after-session interview, some level-3 students admitted that they were not sure of their answers.

\section{The Results from the Grammaticality Judgment Test}

We had another test intending to measure the Japanese learner's ability to identify erroneous usages of basic auditory verbs. The test had 8 items, and the participants were asked to judge whether the sentence given sounds right or wrong. The results are shown in Table $\mathrm{V}$.

TABLE V: THE PERCENTAGE OF CORRECT RESPONSES IN THE GRAMMATICALITY JUDGMENT TEST

\begin{tabular}{|c|c|c|c|c|}
\hline \multirow[t]{2}{*}{ Test Items } & \multicolumn{3}{|l|}{ Levels } & \multirow[t]{2}{*}{ Mean } \\
\hline & $1(n=23)$ & $2(n-22)$ & $3(n=16)$ & \\
\hline $\begin{array}{l}\text { 1. He was listening to the } \\
\text { music. } \\
\text { 2. She suddenly heard a } \\
\text { sound. } \\
\text { 3. We listened to the birds } \\
\text { singing. } \\
4 \text {. He didn't hear } \\
\text { anything. } \\
5 \text {. I listened carefully to } \\
\text { you. } \\
6 \text {. He was hearing the } \\
\text { sound. } \\
7 \text { I heard my father } \\
\text { snoring in the other room. } \\
8 \text {. Suddenly I listened to a } \\
\text { strange noise. }\end{array}$ & $\begin{array}{l}17.4 \% \\
43.5 \% \\
52.2 \% \\
52.2 \%\end{array}$ & $\begin{array}{l}50.0 \% \\
50.0 \% \\
54.5 \% \\
68.2 \% \\
\end{array}$ & $\begin{array}{l}43.8 \% \\
87.5 \% \\
25.0 \% \\
\end{array}$ & $\begin{array}{l}80.3 \\
\% \\
47.5 \\
\% \\
47.5 \\
\% \\
68.9 \\
\% \\
39.3 \\
\% \\
45.9 \\
\% \\
62.3 \\
\% \\
50.8 \\
\% \\
\end{array}$ \\
\hline Mean & $50.0 \%$ & $59.1 \%$ & $57.8 \%$ & $\begin{array}{l}55.3 \\
\%\end{array}$ \\
\hline
\end{tabular}

Here, grammaticality was controlled with the use of adverbs (carefully and suddenly), the adjustment in the progressive aspect (-ing form). The verb listen goes with carefully, but not with suddenly, which collocates with hear (see items 1,2,5). The progressive form is generally possible with listen, but not with hear (see items 1 and 6). In the construction "V + NP + present participle (-ing)," the verb (V) can take either hear or listen, as in items 3 and 7.

As a look at the means of the three level groups indicates, there was no statistically significant difference between the 
levels $(\mathrm{F}(487,2)=2.90, \mathrm{~ns})$. An item analysis showed that the level difference was observed in item $5(\mathrm{~F}(60,2)=4.13$, p $<.05)$ and item $8(\mathrm{~F}(60,2)=3.72, p<.05)$. The level-3 group scored higher than the other two groups.

The level-3 group preferred item 7 over item 3, which accords with the result discussed above in terms of the preemption principle. The sentence "We listened to the birds singing" received relatively low scores across the three level groups. It is, however, worth mentioning that for the level-3 group, it was the only item which cut below the $50 \%$.

Item 5 contains a very common expression "listen to" for Japanese learners. Presumably, familiarity with the phrase "listen to (music)" made many participants believe that nothing can cut in between listen and to, and hence, the sentence with "listen carefully to" was rejected as unnatural.

\section{PEDAGOGiCAl IMPLiCATIONS}

This study studied how Japanese university students understand the meaning and usage of English auditory verbs (listen, hear, and sound), highlighting the three areas of lexical competence-lexical selection, awareness about formulaic expressions, and sensitivity to grammaticality judgment. We observed that the lexical acquisition generally progresses along with the increasing level of proficiency. However, we should note that the results obtained from the high-level students leave a lot to be desired, taking into account the fact that listen, hear, and sound are basic verbs which are generally considered "easy words" to learn.

Then the question will be raised: How do we promote the process of learning the meaning and usage of these basic verbs? There are three pedagogical suggestions. First, in dealing with basic verbs, a distinction has to be made between free usage and conventional usage. A language is a composite of free expressions and formulas. Some expressions using listen and hear, for example, are conventionally used as formulas. The numbers of those formulas are limited within a range of the learnable. Exposure to rich input is necessary to learn formulaic uses of listen and hear. For this, extensive reading may be beneficial to learning formulas, and yet, in an input-poor environment, we cannot simply let it go incidentally [9]. Thus, attention needs to be paid to the formulaic usages in text. Furthermore, we assume that given a list of $\{$ hear from, hear of, hear about $\}$, students will be able to see that the verb hear can take prepositions, and they will know what to memorize. Likewise, in the use of listen, "listen to" is a prototypical exemplar to most Japanese, and the list including "listen up," "listen for," and "listen in (to)" helps them to expand the usage of listen. In this way, students will be able to increase their stock expressions. However, stock knowledge does not automatically transform into flow knowledge, knowledge usable in a flow of natural language processing. Thus, in addition to the systematic treatment of formulaic expressions, we need to contextualize each in an authentic and meaningful way. For example, "Listen up" is a command demanding someone to listen carefully. To put it into context, we urge students to visualize a situation in which a strict teacher is announcing something very important, and says, "This is important. Listen up, you guys!" If a student is able to play the role of this strict teacher, he or she will be able to add an emotive meaning to the expression. In other words, the student will be able to personalize the expression "Listen up." Thus, focus-on-form [10], [11], systematic treatment for awareness-raising [12], and personalization are important factors to consider in order to realize a situation where learners will learn formulas contextually and / or interactively.

Second, acquisition of a verb does not complete with learning the meaning of it. A verb is used in a syntactic construction. For example, listen can be used as an attention-getter as in "Listen, I've got something to tell you." It can be also used in the "verb + NP + the present participle form (-ing)" as in "Let's listen to Mary playing the piano." or the "verb + NP + the bare infinitive form") as in "I listened to Mary play the piano." As a pedagogical implication, the teacher should be aware that vocabulary learning is not simply memorizing the number of words of which the meanings are known. The teacher should urge students to pay attention to the grammatical constructions in which a verb like listen or hear appears, and train them to use the verb in different constructions. Here again, awareness-raising is a key point.

And third, this study showed that native-like lexical intuition, or the ability to differentiate semantically related verbs, is hard to obtain. In an input-poor classroom situation, language learners tend to use "the search-translation-equivalent strategy" [13]. If asked how to learn words in English, our students unanimously answer by saying that they try to equate an English word with the Japanese equivalent. Thus, given a verb like "hear," many Japanese students formulate the "hear = kiku / kikoeru" hypothesis. The verb listen is likely to be associated with Japanese kiku. As a result, some, especially those who understand the meaning of hearing in terms of kiku, confuse listening with hearing. Now, the verb sound is often translated as kikoeru, which makes it difficult to differentiate hear from sound. The search-translation-equivalent strategy fails to differentiate listen, hear, and sound properly. Another strategy often used by students learning a second language in an instructional setting is the exemplar-picking strategy. For example, if a learner encounters the use of listen in "Let's listen to music," the learner will pick "listen to music" as an exemplar. If the exemplar is repeatedly occurs in his or her textbooks, it becomes a reinforced exemplar. On another occasion, the learner will encounter "Listen, I've got something to tell you" and picks that usage of listen as another exemplar, and the list becomes longer in a developmental process. Every time the learner picks an exemplar, he or she uses the search-translation-equivalent strategy, and consequently, the listen in "Listen, I've got something to tell you" receives Japanese nei / ano, as an attention-getter. Likewise, a new exemplar like "Don't listen to him" is associated with "mimi-o kasu" as its translation equivalent. As a result, the learner will formulate the "listen $=\{\mathrm{kiku}$, nei $/$ ano, mimi-o katamukeru hypothesis. The verb hear will be similarly understood with the one-to-many correspondence pattern. As learning proceeds in this manner, the learner will fail to capture the essential difference between listen and hear. As a pedagogical device, [14] empirically showed that the core meaning of a polysemous word assist in its sense acquisition. 
We may call this "a lexical core approach" to teaching the meaning of a polysmous word. The lexical core approach should help students overcome the problems deriving from the use of the search-translation-equivalent and the exemplar-picking strategies. In the case of listen and hear,[15] schematically represented the core meaning of each verb as follows (Fig. 4):
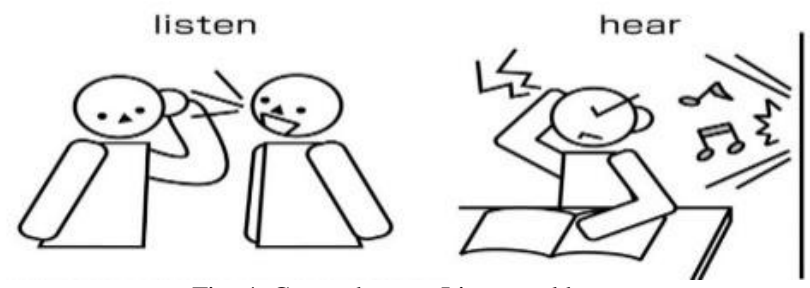

Fig. 4. Core schemas: Listen and hear.

These schematic representations need to be verbally explained. That is, the verb listen involves "paying auditory attention (to capture a sound)", whereas the verb hear implies "capturing something with the hearing organ." The characterization of the core meaning of listen this way explains why listen can be used as an attention-getter or why it often requires the preposition to, which indicates the target to which auditory attention is directed." The semantic contrast between listen and hear with respect to their lexical cores explains the difference between "hearing test" and "listening comprehension test." Semantically, the verb listen does not necessarily include the capturing part (or understanding), and thus, "listening comprehension" is a natural collocation. By contrast, hear does not collocate with "comprehension," and "hearing comprehension" sound redundant. Moreover, "hearing test" usually means a test checking whether the hearing organ works properly. With listen meaning "paying auditory attention," we can explain the following sentence: "I listened hard, but didn't hear anything." Informally, I asked Japanese students to tell the difference between "Listen to my prayer" and "Hear my pray." None of them were able to give the appropriate answer. With the lexical core approach, we can easily explain the difference. "Listen to my prayer" can be used when a father urges his son to learn how to say a prayer, while "Hear my prayer" can be uttered when one prays to God, asking God to take one's prayer.

Some evidence has been reported that schema-based instruction brings better outcomes than translation-based instruction as regards lexical learning [16]. The pedagogical effect of this approach, however, needs to be further checked on empirical grounds.

\section{CONCLUSION}

The aim of this research is to explore the three research questions. As for question (1), English listen, hear, and sound are semantically related. These verbs correspond to Japanese kiku or kikoeru. The participants in this study had about 9-year experiences in learning English, and still found it difficult to differentiate these "basic verbs." Question (2) assumes that language is a composite of free expressions and formulas. Learning formulas are an important part of lexical learning in English. As their level of English proficiency, their knowledge of formulas seems to increase. However, the overall results were far from satisfactory. Some pedagogical devices need to be devised to help students acquire the ability to use formulaic expressions interactively in communication. Question (3) was posed with an assumption that knowing syntactic features triggered by a verb is part of learning the usage of the verb. If the sentence "He was hearing the sound" is shown in isolate of a context of situation, native speakers of English tend to consider it ungrammatical. However, the $55 \%$ of our participants failed to reject it as ungrammatical.

Most Japanese university students tend to consider listen, hear, and sound to be basic and easy words because they encountered them in the initial stages of English learning. This study, though a small-scale one, suggested that more systematic pedagogical treatment should be given in dealing with these basic verbs. For that, the use of the lexical core approach is one possibility, but how and when to use the approach remains to be investigated in the future research.

\section{ACKNOWLEDGMENT}

I would like to express my gratitude to my academic advisor, Professor Shigenori Tanaka, Graduate School of Media and Governance at Keio University, for his support, patience, and encouragement throughout my research paper. He read previous drafts of this paper and provided many valuable comments that improved the contents of this paper. I would like to thank him.

\section{REFERENCES}

[1] T. Takahashi, "A study on lexico-semantic transfer," Ph.D. dissertation, Columbia University, New York, NY, 1995.

[2] S. Tanaka, "The selective use of specific exemplars in second-language performance: The case of dative alternation," Language Learning, vol. 37, no. 1, pp. 63-88, 1987.

[3] Y. Shirai, "Putting PUT to use: Prototype and metaphorical extension," Applied Linguistics, vol. 1, no. 1, pp. 78-97, 1990.

[4] K. Hiki, "An exploratory study into second language learner knowledge of semantically similar lexical items: The case of verbs of perception," Ph.D. dissertation, Indiana University, Bloomington IN, 1995.

[5] Y. Sato and A. Batty, "A Study of learners' intuitions behind the use of utterance verbs in English," Vocabulary Learning and Instruction, vol. 1, no, 1, pp. 29-36, 2012.

[6] A. Rogers, "Physical perception verbs in English: A study of lexical relatedness," Ph.D. dissertation, University of California, Los Angeles, CA, 1973.

[7] N. Gisborne, The Event Structure of Perception Verbs, Oxford, UK: Oxford University Press, 2010.

[8] S. Terasawa, "Focusing on verbs of perception," ARCLE Review, vol. 2, pp. 80-96, 2008.

[9] T. Huckin and J. Coady, "Incidental vocabulary acquisition in a second language," Studies in Second Language Acquisition, vol. 21, no. 2, pp. 181-193, 1999.

[10] C. Doughty and J. Williams, Focus on Form in Classroom Second Language Acquisition, New York: Cambridge University Press, 1998

[11] N. Schmitt, "Tracking the incremental acquisition of a second language vocabulary: A longitudinal study," Language Learning, vol. 48, no. 2, pp. 281-317, 1998

[12] M. Sharwood-Smith, "Consciousness raising and the second-language learner," Applied Linguistics, vol. 2, no. 3, pp. 159-68, 1981.

[13] S. Tanaka and H. Abe, "Conditions on interlingual semantic transfer," On TESOL'84: A Brave New World for TESOL, Washington, DC: TESOL, 1995.

[14] M. Verspoor and W. Lowie, "Making sense of polysemous words," Language Learning, vol. 53, no. 3, pp. 547-586, 2003.

[15] S. Tanaka, S. Takeda, and S. Kawade, E-Gate English-Japanese Dictionary, Tokyo: Benesse Corporation, 1996. 
[16] T. Sato and A. Suzuki, "Do multimedia-oriented visual glosses really facilitate EFL vocabulary learning? A comparison of planar images with three-dimensional images," Asian EFL Journal, vol. 12, no. 4, pp. $160-172,2010$

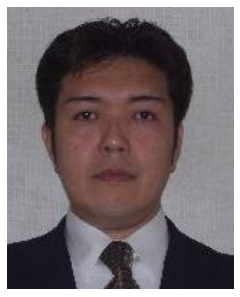

Masanobu Sato was born in Tokyo and raised in Japan. He is now enrolled in the graduate program as a Ph.D. candidate at Keio University, writing his doctoral dissertation on L2 lexical development in Japan. He has been teaching English for more than 8 years, and currently he teaches at universities in Tokyo area. His main research interests are the application of cognitive linguistics to SLA, the development of effective exercises, and minority issues in the age of globalization. His research paper on the topic "A study on the meaning and usage of English auditory verbs by English learners" is one of his interests to explore a further significance finding. The research paper being submitted by him has been undertaken in association with how Japanese learners of English understand the verbs of perception in English with reference to auditory sense. He has worked on the research along with his students to comprehend their ability to use these verbs in context. 